
$0^{2}$
0
$8^{\circ}$
ina $0^{2}$
0
$8^{\circ}$
ina
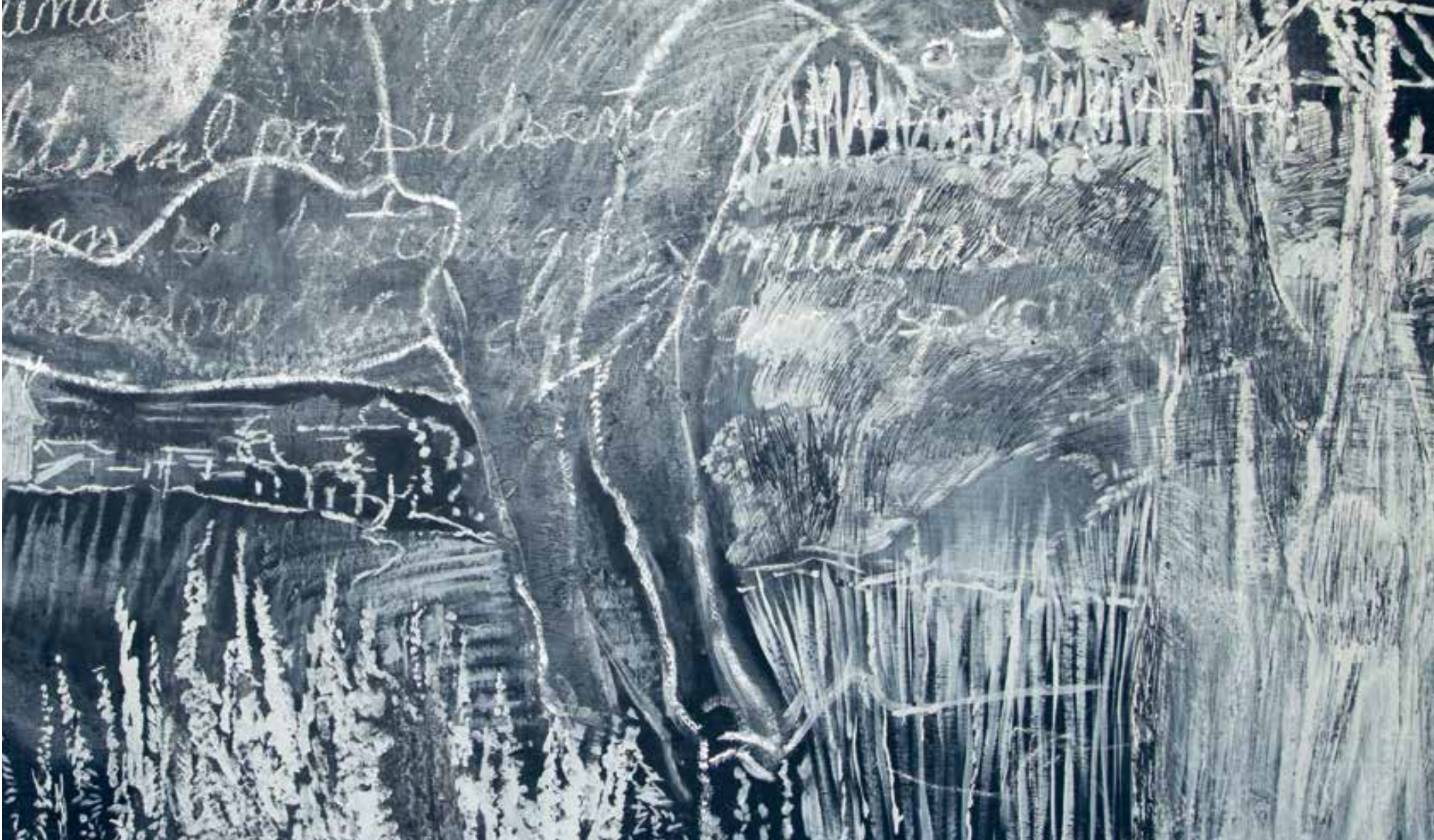

\title{
Investigación en educación
}

artística. Más allá de los riesgos,

\section{la búsqueda por las posibilidades ${ }^{1}$}

Zulma Sánchez Beltrán

Ya es tiempo de buscar mares que nos lleven mas allá de la seguridad de los viejos puertos.

Eisner, 2002, p. 183.

Investigamos para comprender, procuramos comprender a efectos de hacer que nuestras escuelas sean mejores lugares para los niños y adultos que en ellas comparten su vida.

Eisner, 2002, p. 192.

1 Este artículo hace parte de la investigación adelantada en el proyecto de tesis doctoral de la autora en la Universidad Distrital. Se emplearon aquí algunos extractos del capítulo "Antecedentes de la educación artística plástica visual en Colombia: revisión de revistas científicas" del libro Lenguaje, cultura e investigación: 


\title{
Resumen
}

Este artículo surge tras la búsqueda y la reflexión de metodologías de investigación en el ámbito educativo, específicamente desde la educación artística, y se encuentran tanto las dificultades propias de la tradición investigativa y quienes ostentan su saber, como las posibilidades, pluralidades de flexibilización, integración y polisemia de diferentes métodos de investigación respecto de la investigación cualitativa para el caso en mención. Apunta a reflexionar y comprender en torno de la tradición investigativa sus conexiones y posibles adaptaciones para el caso de la investigación pedagógica, a través de las artes plásticas y visuales.

Inicialmente se traza un breve mapeo de la tradición investigativa en ciencias sociales, para dar lugar a la investigación educativa, distinguiéndola de la investigación pedagógica. Se centra la reflexión en torno a la investigación educativa y pedagógica artística, focalizándola en lo que tiene que ver con las artes plásticas y visuales para el caso de la escuela. Allí se plantea finalmente la investigación pedagógica a través de las artes visuales, y se le da apertura al debate, las nuevas miradas y voces hacia la redefinición y consolidación de lo que implicaría o supondría la investigación educativa y pedagógica artística en general, y cada lenguaje en particular.

Palabras clave: educación artística; artes plásticas y visuales; investigación; pedagogía.

\section{Research in Artistic Education. Beyond Risks, the Search for Possibilities}

\begin{abstract}
This article is the result of a research and the reflection on research methodologies in the field of education and specifically from the perspective of arts education. Findings show the difficulties of the research tradition and those who flaunt their knowledge, and the possibilities, pluralities of flexibility, integration and polysemy of different research methods of qualitative research regarding the case in question. The paper aims to ponder and understand the tradition of research, its connections and possible adjustments in the case of educational research through the plastic and visual arts.

First, a brief mapping of social science research tradition is made to show educational research, distinguishing it from educational research. The reflection focuses on educational research and/or artistic teaching, focusing on plastic and visual arts, in the case of school where, finally, educational research through the visual arts is proposed, paving the way to debate new perspectives and voices to the redefinition and consolidation of what would involve both educational and artistic teaching research, in genera,l and each language, in particular.
\end{abstract}

Keywords: art education; plastic and visual arts; research; teaching.

\section{Pesquisa em educação artística. Além dos riscos, a busca das possibilidades}

\section{Resumo}

Este artigo nasce da busca e reflexão de metodologias de investigação no âmbito educativo, especificamente desde a educação artística. Encontram-se tanto as dificuldades próprias da tradição investigativa e quem ostenta seu saber, quanto das possibilidades, pluralidades de flexibilização, integração e polissemia de diferentes métodos relacionados com a investigação qualitativa para este caso. Visa compreender e refletir sobre a tradição investigativa, seus vínculos e possíveis adaptações para o caso da pesquisa pedagógica, através das artes plásticas e visuais. Inicialmente, é elaborado um breve mapeamento da tradição investigativa em Ciências Sociais para dar lugar à pesquisa educativa, distinguindo-a da pesquisa pedagógica. Centra-se na reflexão sobre a pesquisa educativa ou pedagógica artística, focalizando-a nas áreas relacionadas com as artes plásticas e visuais no caso da escola. Finalmente, expõe a reflexão através das artes visuais e abre o debate, os novos olhares e vozes para a redefinição e consolidação daquilo que implicaria ou suporia a pesquisa educativa e pedagógica artística em geral, e cada linguagem em particular.

Palavras chave: educação artística; artes plásticas e visuais; pesquisa; pedagogia. 
Plantear investigaciones en educación artística resulta, para algunos, una gran insolencia (los fundamentalistas metodológicos), lo cual hace que sea complejo en doble sentido: por un lado, desde lo educativo, campo de joven reconocimiento en la tradición investigativa, y por el otro, en el campo del arte con más reciente inicio en esta, al menos en la investigación legitimada científicamente. Resulta entonces, para la mayoría, una redundancia de ausencias en doble sentido, dada la falta o, mejor, "reciente" incursión de la educación, y por ende de los educadores, en el campo investigativo, especialmente para el caso de la escuela, y por el otro lado, la misma situación pero desde el ámbito artístico y los artistas.

Para los dos casos es posible afirmar que las investigaciones realizadas, en su mayoría, han sido hechas sobre la educación y sobre el arte, es decir generadas por los expertos e investigadores, generalmente ajenos a los contextos educativos del aula, pero involucrados en la conceptualización, las directrices y las políticas educativas; el mismo panorama aparece para las artes, generalmente tratadas e investigadas por filósofos, historiadores, antropólogos y sociólogos, es decir quienes hacen parte de la tradición y trayectoria investigativa convencional y legítimamente conocida en ciencias sociales, pero hay pocas investigaciones hechas desde las artes, o a través de estas, por los propios artistas, desde el quehacer mismo y específico del lenguaje que sea.

Tal como se había señalado,

Plantear la investigación artística o investigación en educación artística (para el caso específico), supone un asunto muy polemizado, y también emergente, por lo tanto, las discusiones apenas comienzan, y la mayoría está anclada al debate sobre el pacto de Bolonia². Según autores como Hernández (2006) y Uhía ${ }^{3}$ (2010) la investigación tanto en artes como en educación artística, ha estado

2 Declaración hecha y firmada en Bolonia (1999), por varios países europeos, la cual supone la creación y legitimación del espacio europeo de educación superior, convirtiéndose en la base rectora y referencial de las reformas educativas para los demás países, "si quieren" ser acreditados internacionalmente. Dentro de sus principales objetivos están: la implantación de un ciclo educativo ascendiente: pregrado, maestría, doctorado y posdoctorado; instalación del Sistema Europeo de Transferencia de Créditos (ECTS), lo que permite la homologación en todas las universidades de la Unión Europea y unos tiempos acelerados para cursar las carreras. En últimas, se promueve una dimensión europea de la educación superior.

3 Profesor asociado del Departamento de Arte de la Universidad de los Andes, Bogotá. Artista, MFA del San Francisco Art Institute de California y Maestro en Bellas Artes de la Universidad Jorge Tadeo Lozano de Bogotá. siempre presente de una $u$ otra manera, donde ha supuesto una actividad fomentada, más no exigida, ni evaluada. Sin embargo, la exigencia y evaluación de la misma -investigación-, comienza y se articula para todos los campos en general, y para el campo del arte en particular, en países como Colombia desde dicha declaración; con la cual, se exige, evalúa y legitima la investigación según estándares internacionales de acreditación de la educación.

Pese a ello y de manera simultánea para el caso del arte, e incluso de la educación artística, se ha estado en constante búsqueda sobre caminos y metodologías propias de investigación, dado el carácter "subjetivo" que lo determina. Para los autores referidos anteriormente, entre otros, no es posible medir la investigación en artes y por ende en educación artística con los mismos parámetros que se aplican a otros campos del conocimiento. Sin embargo, tras las exigencias condicionadas por la declaración de Bolonia, se ha optado además de la búsqueda de metodologías propias, por la adaptación y aplicación de metodologías investigativas de otros campos con mayor trayectoria en esta, tomadas de metodologías de tipo cualitativo, cuestionando y debatiendo en torno a "la investigación sobre las artes, sino desde las artes" (p. I4), como lo señala Hernández (2006).

De esta manera, se establece que la investigación sobre las artes ha sido y puede ser hecha desde la experiencia artística del espectador (en tanto interprete, más no creador), de quienes estudian o leen las obras; por lo tanto como modos y formas de lectura e interpretación artística, pero no desde su creación. Es decir la investigación desde las artes, supondría más allá de la experiencia artística interpretativa, del encuentro con la obra ya terminada (lectura e interpretación como espectador), se considera y asume a partir de la creación y sus propios creadores, desde los artistas no sobre estos, los artistas, quienes originan, realizan y ejecutan la obra, sus procesos creativos, asumidos también como procesos de investigación; más allá de los estudios históricos o hermenéuticos sobre las problemáticas, producciones, o prácticas artísticas, realizadas en su mayoría por historiadores, filósofos, antropólogos, entre otros, no por los propios artistas, ni mucho menos de sus procesos artísticos creativos. (Sánchez, 20I4, p. II5). 
No cabe duda que en el ámbito educativo, desde el aula, y en el artístico, desde el taller, educadores y artistas han realizado investigación cada uno a su manera, pese a las múltiples resistencias entre la legitimación, desaprobación y muchas veces exclusión del paradigma dominante. Según Denzin,

Teniendo que limitar las formas de conocer a las ya tradicionalmente avaladas, pese a la calidad o sentido inicial de la investigación y por ende condicionarla a sus modelos histórico de división, jerarquización, ordenación, distribución según el paradigma dominante. Un campo definido por tensiones, contradicciones y vacilaciones esenciales, definiciones y concepciones que compiten entre sí y se alijan dentro y fuera del mismo. (Denzin, 2012a, p. 27).

Esta situación se hace cada vez más evidente y compleja, como ya se mencionó, bajo los nuevos modelos de acreditación y certificación de las universidades y la investigación que en estas se realiza. Se han generado formas y modos específicos, delimitados y modelados del quehacer investigativo, por eso han tenido que adaptarse campos como la educación y, especialmente, el arte a los protocolos y procedimientos dados por estos; así, ambos sin tener una trayectoria o tradición propia en investigación desde su propio campo se han visto abocados a apelar y tomar en préstamo las rutas delineadas histórica y tradicionalmente como investigación. También se enfrentan a la propia definición del campo a la que se ven sometidos, es decir, tanto la educación como el arte en sí mismos y de manera aislada suponen campos bien definidos, pero hablar de la educación artística supone un campo emergente, y, por lo tanto, apenas en construcción y definición, lo que suma a la complejidad de plantear la investigación en educación artística y, por ende, sus metodologías.

Se reitera que concebir la investigación en educación artística redunda en dos grandes asuntos que apenas comienzan, de manera separada y a la vez conjunta, la larga y ardua trayectoria investigativa, en los términos y condiciones como hoy se legislan y exigen. Según Denzin (2012a, p. II),

Los procesos de investigación, mucho más para el caso latinoamericano están habitualmente marcados por orientaciones epistemológicas, teóricas, metodológicas originadas fuera de sus límites pero a las que los investigadores necesitan recurrir si aspiran a que sus trabajos y reflexiones excedan esos mismos límites. Tal apelación opera aún en los casos en que las particularidades históricas, culturales, sociales, económicas políticas, entre otras, de las situaciones que estudian les imponen la exigencia de acudir a otras formas de conocimiento y, por tanto, a otros presupuestos ontológicos y epistemológicos que las sustenten.

Con esto se afirma que, si bien la investigación de las ciencias sociales ha estado anclada históricamente a disciplinas y valoraciones normativas, también ha sido sometida a una constante revisión de sus modelos y regímenes a fin de ampliar y expandir sus metodologías, métodos y sentidos de la investigación. Esto da lugar a diversas formas de conocer que hacen resistencia a los regímenes consolidados, las cuales son más colectivas y socialmente construidas, y modifican las estructuras y formas naturalizadas de organizar y producir conocimiento o investigación; lo anterior le da prioridad a las voces de los participantes, a otras maneras de ser, hacer y comprender, e impulsa la transformación social, revisando y redefiniendo las características, diseños, fines y sentidos de la investigación. 


\section{Tradición y trayectoria investigativa}

La investigación en ciencias sociales ha sido tradicionalmente asociada ${ }^{4}$ con el paradigma positivista y fundacional sobre todo de finales del siglo xIX y comienzos del xx, conocido también como etnografía temprana (etnografía colonial del siglo XVII-XVIII-XIX, etnografía de los indígenas norteamericanos, antropología en el siglo XIX). Sobre esta se generaron complejas críticas a nivel epistemológico y ético tanto desde el movimiento reformista de los años sesenta, como desde los paradigmas emergentes de la época (interpretativo y crítico), con los que se dio lugar a la investigación cualitativa. Según teóricos como Denzin (20I2a), Vasilachis (2009), entre otros, la investigación cualitativa, en tanto su nominación, obedece a dicho movimiento, además de a la influencia sociológica del trabajo de la Escuela de Chicago en 19201930, con la cual se estableció la importancia de la investigación cualitativa para el estudio de la vida de los grupos humanos (estudios de comunidades y etnografías de los inmigrantes en Estados Unidos). También se nutre de los aportes realizados desde la antropología por Margaret Mead (I975), Malinowski (1984), entre otros, quienes definieron los marcos de la disciplina y las líneas principales de los métodos del trabajo de campo; este momento se conoció como la etapa modernista o edad dorada (I950-1970), y posteriormente dichos métodos fueron utilizados en otras disciplinas más allá de las ciencias sociales, como el caso de la educación.

Aparecióluego loque algunos autores denominan el desdibujamiento de los géneros a mediados de los años ochenta, como consecuencia del pospositivismo, en el que las humanidades se convirtieron en un recurso central para la teoría interpretativa crítica, y las líneas generales de la investigación cualitativa comenzaron a gestarse, convirtiéndose en un bricoleur interpretativo (hasta el presente debate posmoderno y posestructuralista): "Sociólogos, antropólogos y educadores siguen explorando nuevas formas de hacer etnógrafa, escribir ficción, teatro, textos para representaciones y poesía etnográfica" (Denzin, 20I2a, p.25), con lo cual retoman recursos de diferentes disciplinas, lo que implica migraciones reciprocas entre los humanistas y las ciencias sociales. Los humanistas migraron a las ciencias sociales en búsqueda de nuevas teorías y formas de estudiar la cultura popular y sus contextos locales, etnográficos; por su parte, los científicos sociales se volvieron hacia las humanidades con la esperanza de aprender a realizar lecturas estructuralistas y posestructuralistas complejas de los textos sociales.

4 Sumado a las evidentes pugnas entre la investigación cuantitativa y cualitativa, en las que esta última quedaba relegada a un estatus subordinado por el saber científico. Las ciencias y las humanidades: un tema antiguo, gastado inclusive. Dice Brunner (1988), "Nuestro otrora gastado tema parece haber vuelto a despertar [...] o quizás jamás ha estado dormido solo en silencio pensando y actuando". Según Brunner, la vieja discusión ha pasado de los productos de la investigación científica y humanística a los procesos de investigación mismos. El conjunto de conocimientos objetivos comprobables de la ciencia ya no se han enfrentado tan sencillamente con los productos subjetivos, hipotéticos e inconsistentes de las humanidades. Sus procedimientos ahora nos invaden. Las ciencias y las humanidades han llegado a ser apreciadas como productos ingeniosos de las mentes de los hombres, como creaciones generadas por diferentes usos de la mente (I988, p. 54). Parecería que la ciencia y las humanidades comienzan en algún punto convergente y se separan en lo que se refiere a sus métodos; aunque pueden tener un origen común, se separan y especializan con diferentes objetivos en lo que se refiere a la construcción de universos. La ciencia trata de construir un mundo que permanezca invariable a pesar de las intenciones y los conflictos humanos. En cambio, el humanista se ocupa principalmente del mundo y de los cambios que experimenta según la posición y la actitud del espectador. La ciencia crea un mundo que tiene la existencia ligada a la invariabilidad de las cosas y los acontecimientos frente a la transformación de las condiciones de vida de aquellos que tratan de comprender. Las humanidades tratan de comprender el mundo en tanto en este se reflejan las necesidades que implica el hecho de habitarlo.
Con el desdibujamiento de los géneros también se dio la crisis de la representación, la cual se ubicó en la autorreflexión de los investigadores y los investigados, y generó cambios en los estilos, el género, la epistemología, la ética, la política y la estética de la investigación. Tuvo su punto más álgido en lo que Denzin (20I2b) ha denominado el posmodernismo investigativo, el periodo de la gran transformación o revolución desde 1990 hasta hoy, en el que han surgido nuevos modos de etnografías experimentales e investigación posexperimental, caracterizados tanto por el giro narrativo, las narraciones y nuevas sensibilidades, como por la duda y el rechazo a privilegiar un método o teoría, "Donde al mismo tiempo, una gran variedad de nuevas perspectivas interpretativas y cualitativas tomaron vuelo, incluyendo la hermenéutica, el estructuralismo, la semiótica, la fenomenología, los estudios culturales y el feminismo tuvo lugar también una suerte de diáspora metodológica" (2012a, p.48).

Dentro de las nuevas alternativas emergentes en investigación, según Denzin (20I2b), se pueden citar el proyecto metodológico indigenista como metodología de descolonización; la etnografía crítica; el humanismo crítico; la teoría queer; la etnografía performativa; los estudios narrativos; la investigación basada en el arte; la etnografía online; las poéticas cultuales, entre otras, las cuales se han situado en las fronteras entre el pospositivismo (los informes del mundo son solo parcialmente objetivos) y el posestructuralismo, y se han fusionado como bricoleurs interpretativos (haciendo uso de estrategias de investigación, como estudios de casos, etnografía, fenomenología y teoría fundamentada).

Dicha revolución obedece, a su vez, tanto a los cambios y transformaciones del propio mundo y fuera de la academia que investiga, como a la creciente sofisticación teórica y metodológica de los investigadores cualitativos: "pensar el objeto de investigación más allá de la nación o el grupo local. Ya no existe una identidad etnográfica consolidada, el etnógrafo trabaja con realidades híbridas" (Denzin, 20I2a, p.36).

Se habla así de una revolución metodológica a lo largo de los últimos veinticinco años, en la que los límites entre las distintas disciplinas además de desdibujarse se han mezclado o, en palabras de Denzin, hibridado en éxodos recíprocos de metodologías y técnicas adoptadas de las ciencias sociales y humanas, lo cual resulta en bricoleurs interpretativosa (categoría reiterada por el autor): "la investigación cualitativa que cruza la frontera posmoderna le exige al académico que abandone todos sus prejuicios, valores, teorías y perspectivas preestablecidas" (2012a, p.79).

\section{Investigación educativa o investigación pedagógica}

Ante dicho panorama, Denzin (2I02b), Herrera-González (2010), Eisner (1998a) y Hernández (2006) comparten la idea de que es gracias al surgimiento de los paradigmas hermenéutico 
y crítico en las ciencias sociales, y por ende, un distanciamiento del modelo positivista, y la posibilidad de construir conocimiento científico desde la práctica, que se "permiten pensar en una praxis social5 que se encuentra en capacidad de producir conocimiento sobre sí misma, de manera que la objetivación de la práctica por medio de la investigación no se lleva a cabo en las coordenadas de una separación entre la práctica y la teoría" (Herrera, 20IO, p. 58); con esto, es posible para el caso de la educación y la pedagogía definir su objeto de estudio de nuevas maneras, más allá de las experimentales. Según Elliot (2005), con el auge de métodos cualitativos de investigación se da lugar a la investigación educativa, yendo más allá de la etnografía, y para el caso de la investigación educativa se acoge la investigación para la acción, de la cual hacen uso los docentes internalizados en la escolaridad, asumiendo el aula de clase como el contexto de la investigación y el quehacer como docentes y el de sus estudiantes como protagonistas:

El conocimiento validado en estudios de diseño cuantitativo y experimental, el modelo cualitativo experimental difícilmente puede orientarse al examen de los contextos complejos y dinámicos de la educación pública en sus muchas formas, entornos y variaciones, especialmente tomando en consideración [...] las sutiles diferencias sociales que resultan del género, la raza, la etnia, el status lingüístico o la clase social.

(Denzin, 20I2a, p. 27).

De la misma manera, tanto para Denzin (2012b), como para Herrera (2010) y Calvo, Camargo-Abello y Pineda-Báez (2008), aunque el conocimiento educativo y pedagógico se inscribe, mediante la investigación, en campos teóricos sobre los que existen construcciones previas, en tanto epistemologías y estatutos de verdad establecidos que admiten y validan aquello que estudia o trabaja un determinado saber o disciplina; la particularidad de la investigación educativa y pedagógica es el escenario para dar significado al hecho educativo y escolar, para actuar sobre él, con el fin de construir miradas y sentidos propios, generar y abrir nuevas formas de comprensión de la investigación y metodología aplicada y específica desde el propio campo (educativo y pedagógico), más allá de la adquisición de herramientas técnicas de procesamiento y análisis de datos, los cuales suponen recursos metodológicos posibles de ser apropiados.

Entonces se plantea y se da la posibilidad de producción de conocimiento desde el quehacer propio de los docentes como investigadores y su saber pedagógico, con lo cual configuran las prácticas educativas y pedagógicas, y desplazan la mirada positivista o desde los fundamentalismos metodológicos de la psicología o la sociología, entre otras, que, según Herrera (20I0, p. 58), "miran los fenómenos educativos desde categorías que no se anclan en la experiencia misma de los actos educativos":

La investigación sobre los fenómenos educativos estuvo delimitada por el enfoque explicativo causal de las

5 Se entiende la ciencia social como las relaciones de comprensión, interpretación y análisis entre el investigador y la realidad social para el caso educativo que estudia; más que una práctica social, en este caso supone una práctica educativa o pedagógica desde la cual es posible la construcción del conocimiento de manera específica para el campo en particular. 


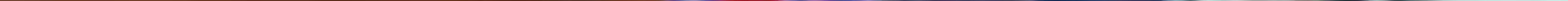


ciencias de la educación. Este enfoque se propone la construcción de un conocimiento teórico de validez universal. Por ello, apunta a identificar las regularidades que se encuentran en la base de los fenómenos educativos y a formularlas en términos de modelos explicativos que encuentran su validez en la evidencia empírica. (Herrera, 20I0, p. 58).

Allí la pedagogía y las acciones educativas se convirtieron en objeto de estudio a partir de la preeminencia del método hipotético-deductivo, que consiste en formular hipótesis desde un cuerpo de conceptos ya constituido y en contrastar esas hipótesis con la realidad, por medio de experimentos. Se asume entonces la educación solo como un campo de aplicación de teorías psicológicas, sociológicas o antropológicas: "En este sentido, la explicación de los fenómenos educativos se da en términos de los conceptos propios de estas ciencias, con lo cual se pierde la especificidad de las prácticas pedagógicas" (Herrera, 2010, p. 58).

Ahora bien, se requiere diferenciar entre investigación educativa e investigación pedagógica, ya que esta última es para los autores mencionados (Herrera, 20I0; Calvo et al., 2008; Eisner,1998a; Elliot, 2005) propia del maestro, en tanto maestro investigador; al realizar esta distinción se busca, más que diferenciar dos campo de conocimiento, distinguir entre dos tipos de investigación e investigadores ${ }^{6}$. Para Calvo et al. (2008) y Herrera (2010), la investigación educativa supone la producción de conocimiento sobre planteamientos ampliados y globales de los fenómenos educativos, con lo cual se asume la escuela y lo que en esta sucede como un microcosmos que da lugar o revierte lo que sucede en el macro, es decir las relaciones entre educación y sociedad. En cambio, la investigación pedagógica supone el escenario desde el cual los propios maestros reflexionan sobre los procesos de enseñanza-aprendizaje en sus aulas de clase, con sus propios procesos, encuentros y desencuentros pedagógicos que suman el día a día del quehacer docente respecto a lo que hacen, cómo lo hacen, con quién, es decir, qué enseñan, cómo lo enseñan, por qué medios, pero también qué se aprende, cómo se aprende, quiénes lo aprenden y por qué. La investigación pedagógica estrecha y vincula la teoría y la práctica como aspectos constitutivos de la misma realidad tras la autoindagación, observación y cuestionamiento constante, que busca construir no solo conocimiento "científico" sino, sobre todo, saber pedagógico.

6 Según Calvo et al. (2008), la investigación pedagógica caracteriza y es propia del maestro, tras la apuesta y empoderamiento del maestro investigador, debate que "ha sido el eje de discusiones llevadas a cabo en el país en diferentes momentos. La investigación como práctica pedagógica fue la propuesta debatida y difundida a través del Convenio Andrés Bello ( $\mathrm{CAB}$ ) y en ella se mostró la amplitud de posibilidades que la investigación representa para la cualificación de la práctica del maestro, entendida como práctica pedagógica (CAB, 1999). Más recientemente, el Instituto para el Desarrollo de la Ciencia y la Tecnología, Francisco José de Caldas (Colciencias) convocó a un grupo de investigadores para discutir la investigación que hacen los maestros, como un debate más allá de los métodos, que implica navegar y afrontar la incertidumbre (Hernández, 2005) y que tienen en el aula (Vasco, 2005) y en la investigación cualitativa (Camargo, 2005), una fuente de posibilidades que redundan en mejores prácticas pedagógicas (2008.p.I65)".
Según Herrera (2010), la investigación pedagógica redefine su propio estatuto disciplinar desde dos instancias diferenciadas pero convergentes, con lo que da cuenta tanto de la tradición reflexiva sobre la educación como fuente de sus indagaciones y conocimientos, como el rescate de las prácticas pedagógicas como objeto de estudios en tanto prácticas históricas y políticas; logra articular la teoría y la práctica; y conjuga los hallazgos de las prácticas pedagógicas con los modelos teóricos. Según el autor,

Ahora, la pedagogía busca desentrañar el sentido de su propio discurso para iluminar, precisamente, las prácticas a las cuales ese discurso ha dado lugar. Y a la vez, en las prácticas pedagógicas, la pedagogía encuentra el ámbito de contextualización y reconfiguración del discurso pedagógico. Esto quiere decirque las prácticas pedagógicas son asumidas como prácticas cuyo sentido y significado se obtiene al menos teniendo en mente cuatro dimensiones: la intención de quien la realiza, el significado que tiene para quienes participan de ella, la historicidad de sentido de la que la práctica hace parte y la relación de la práctica con las estructuras sociales y políticas que se expresan en ella (Kemmis, citado en Carr, 1996). Vistas así, las prácticas pedagógicas son la fuente de la que brota el discurso sobre la pedagogía. Al mismo tiempo, el discurso pedagógico cobra sentido en la medida en que apunta a una transformación de las prácticas. (Herrera, 20Io, p. 6o).

Se afirma así que la investigación pedagógica tiene por objeto la explicitación del saber pedagógico que para su crecimiento, posicionamiento y consolidación requiere investigación, en procura de comprender y transformar sus propias prácticas pedagógicas. Dichas prácticas, más allá de una práctica mecánica e instrumental, suponen eventos de lenguaje y comunicación plenos de significados susceptibles de convertirse para el maestro-investigador en textos pedagógicos para ser leídos e interpretados dentro y en su propia constitución -la práctica pedagógica-. Así, el maestro no solo contribuye al saber pedagógico sino que constituye el saber pedagógico, en el que, según Calvo et al. (2008), dichos procesos son sistematizados por ellos mismos, lo cual permite avanzar en la construcción y la circulación del saber pedagógico.

Ahora bien, dicho saber está directamente afectado por la disciplina propia del maestro, tanto designación o especialidad de una disciplina científica, como objeto 
de estudio complejo desde el saber pedagógico, es decir la práctica misma de enseñarla, la exigencia o demanda de la política educativa, y la dimensión social y cultural de la sociedad e institución en que se enseña. Esto es así pese a la posible pluralidad metodológica que tiene la investigación educativa, en tanto en sus objetos de estudio y en la convergencia de múltiples disciplinas en su comprensión y explicación, según Touriñan-López (2008), podrían establecerse diversas formas de racionalidad como la científico-tecnológica, la práxica, la teológica y la literaria y artística, en tanto formas y dimensiones del conocimiento con peculiaridades, criterios y conceptos propios: "Cada forma de conocimiento tiene sus peculiares modos de prueba acerca de la verdad y validez de sus proposiciones" (Touriñán, 2008, p. I77). Cada racionalidad integra diferentes disciplinas y cada disciplina se constituye en función de su objeto de estudio, con ámbitos de realidad muy específicos y diferentes. Por ello para el caso específico de este artículo se focalizará en la racionalidad literaria y artística, específicamente la investigación pedagógica a través de las artes plásticas y visuales.

\section{Investigación educativo-pedagógica artísticamente trabajada}

Tal como se ha reiterado con Denzin (20I2b), Herrera (2006), Eisner (1995,1998a,2002) y Elliot (2005), resulta muy complejo, casi "improbable, asimilar la enseñanza a una ciencia", asumida como la práctica de procedimientos estandarizados aplicables de manera sistemática para obtener resultados predecibles, una y otra vez. Aunque el método científico pueda brindar algunas relaciones entre variables aplicadas al campo educativo, su utilidad, según los autores, se reduce, pues dista muchas veces de la marcha real y los contextos del aula, de ahí la necesidad de apelar a otras formas de investigación no solo cualitativas sino artísticamente trabajadas, en las que el docente, desde su especialidad, está en capacidad de dar los aportes particulares y específicos de la disciplina artística. No se trata de rechazar las generalizaciones o la búsqueda de estas, sino de instar a la complejidad de la investigación educativa y, en particular, artística.

De la misma manera, Eisner (1995,1998a,2002) y Viadel (2005) insisten en que es gracias a los cambios y transformaciones en las concepciones sobre el saber como propiedad exclusiva del discurso científico y, en consecuencia, la crisis epistemológica respecto a verdades universales, metarrelatos, grandes paradigmas y realidades objetivadas, que ha sido posible la inclusión de las humanidades, y de manera más reciente las artes, como escenarios desde los cuales es posible "ampliar la comprensión humana y que los fenómenos mismos que eluden el significado literal a menudo son mejor revelados por la expresión poética y la imagen visual" (Eisner, 2002, p. I5I).

A la vez los dos autores (Viadel, 2005; Eisner,1995,2002) coinciden en que aunque hablar de la investigación basada en artes supone un método muy reciente, enunciado apenas en los años noventa, comienza a tener reconocimiento dentro de la comunidad académica de las ciencias humanas y sociales "como una línea más novedosa y arriesgada de investigación dentro de las metodologías cualitativas" (2005, p. 248), y es asumida por "jóvenes investigadores como medio de pensar y llevar a cabo investigaciones educativas" (Eisner,2002, p.I52) desde disciplinas artísticas. Se convierte entonces en una línea metodológica de los paradigmas de investigación emergentes o paradigmas alternativos, en los cuales se debaten problemas y exploran métodos que antes ni se tenían en cuenta, lo que implica crear nuevas maneras de realizar investigación, y otros métodos y formas de conocer y hacer, en los cuales diferentes formas requieren distintas expectativas.

Al contemplar otros métodos, en tanto diferentes formas de conocer y hacer, se genera una gran pluralidad conceptual comparable con las inteligencias múltiples de Gardner (2005), según las cuales existen múltiples modos de conocer y se asume una visión cultural de la mente, en la que la inteligencia no es solo una sino que son muchas. Según Eisner (2002, p. 157),

la cognición como proceso por el organismo cobra conciencia, con frecuencia ha sido identificada con el pensamiento lingüísticamente transmitido, sin embargo el pensamiento y el conocimiento son transmitidos por cualquier tipo de contenido experiencial que generen los sentidos, la vida cognitiva depende de la experiencia de cada quien "la cognición es más amplia que las palabras, y las formas a través de las cuales le damos un status público son tan diversas como las formas sociales de representación que usamos en la cultura para transmitir significados".

Con los nuevos paradigmas y métodos, cambia la comprensión de las fuentes de acción, lo cual da lugar a la intuición y al pensamiento cualitativo, al arte comolugar de partida de la enseñanza y aprendizaje; en últimas se dan diversos modos humanos de pensar y conocer, más allá de la estreches de la racionalidad técnica y competente se ve la racionalidad literaria y artística, creativa y afectiva en la enseñanza, la estética. Se asumen los modos no científicos, y se reclama una visión del conocimiento más amplia y pluralista, nociones menos estrechas y dogmáticas sobre el saber, en las que los modos científicos no son las únicas maneras de comprender y entender el mundo, y por el contrario existen nuevas y diversas formas de acceder a él, en este caso el arte, descartado y aislado del campo científico por su naturaleza afectiva, desconociendo sus funciones epistémicas (herencia de la distinción entre sentimiento y conocimiento, y se excluye el sentimiento como fuente de conocimiento, tratado como residual). Según Eisner (2002), se ancla "una profunda incomprensión de las fuentes de conocimiento. Las formas de representación utilizadas en las artes transmiten significados que otros campos no tienen esa impronta" (p.I57). La ciencia enuncia significados, el arte los expresa (Dewey (2008) y Eisner (1995, 1998b, 2002). Las artes y las formas de representación son recursos funcionalmente únicos, y el reconocimiento de sus aportes a la cognición potencializa el currículum (modificador de la mente). 
El rasgo distintivo de la investigación en educación artística es su objeto de estudio. Los temas, los asuntos y los problemas sobre los que centra su atención la investigación en educación artística son los de la enseñanza-aprendizaje de las artes, para este caso las culturas visuales y su sensibilidad respecto a las cualidades sensoriales de los fenómenos y situaciones educativas que se estudian; además, generan otras maneras de descubrimiento e indagación sobre los problemas educativos. Se asume el hecho artístico más allá de la obra como proceso de creación, recreación, reconocimiento e interpretación, desde el cual se brindan herramientas de creación de significados, y construcción e interpretación de realidades.

Según Viadel (2005), el primer congreso de investigación educativa basada en artes tuvo lugar en Albuquerque, Nuevo México, en febrero del 2000, con la participación de ponentes como Tom Barone, Eliot Eisner, Patrick Diamond y Carol Mullen, lo que da lugar a la “investigación educativa basada en artes". Eisner es uno de los grandes abanderados, para quien la investigación artística podría resultar una tercera tendencia investigativa, después de la cuantitativa y la cualitativa; afirma también que la investigación educativa artística (IEA) supone un espacio idóneo y propicio para el desarrollo de la arte-investigación educativa o investigación educativa basada en las artes visuales.

Así mismo, Eisner (1995,2002) plantea que la investigación educativa artísticamente trabajada puede ayudar a entender la escuela en la medida en que contribuye a potenciar diversas formas de representación que inciden en las experiencias y, por lo tanto, pueden modificar las maneras de entender el mundo. Dichas formas suponen recursos potenciales de informar y conocer, que esto suceda o no depende de la manera como se usen; el modo de trabajar una forma de representación depende de la habilidad artística, pues su tratamiento artístico es el medio para generar impacto, aclarar ideas e imágenes, con lo que se ejercen efectos y afectos sobre quienes leen dichas formas. Así, puede decirse que la investigación educativa artísticamente trabajada es la que emplea una o más de estas formas como medio fundamental de comunicación. Para Eisner (2002) el uso de este tipo de metodologías tiene implicaciones conceptuales, y cambios en las maneras de concebir el conocimiento, la mente, la inteligencia y la cognición:

Una obra de arte presenta el sentimiento para nuestra contemplación, haciéndolo visible o audible o perceptible de alguna manera a través de un símbolo, no inferible de un síntoma. La forma artística es congruente con las formas dinámicas de nuestra vida sensorial, mental y emocional directa; las obras de arte son proyecciones de la vida sentida. (Langer, 1976, citada en Eisner, 2002, p. I8I).

Así, pese al constante enfrentamiento entre lenguaje verbal y lenguaje visual, los dos son instrumentos de conocimiento, al igual que sus posibilidades en cuanto a la descripción, representación y abstracción e interés en la experiencia, el significado y la comprensión. Para Brunner (1998), las artes y la educación artística podrían establecerse como modos estéticos de conocer, y son distinguibles dos grandes formas de 


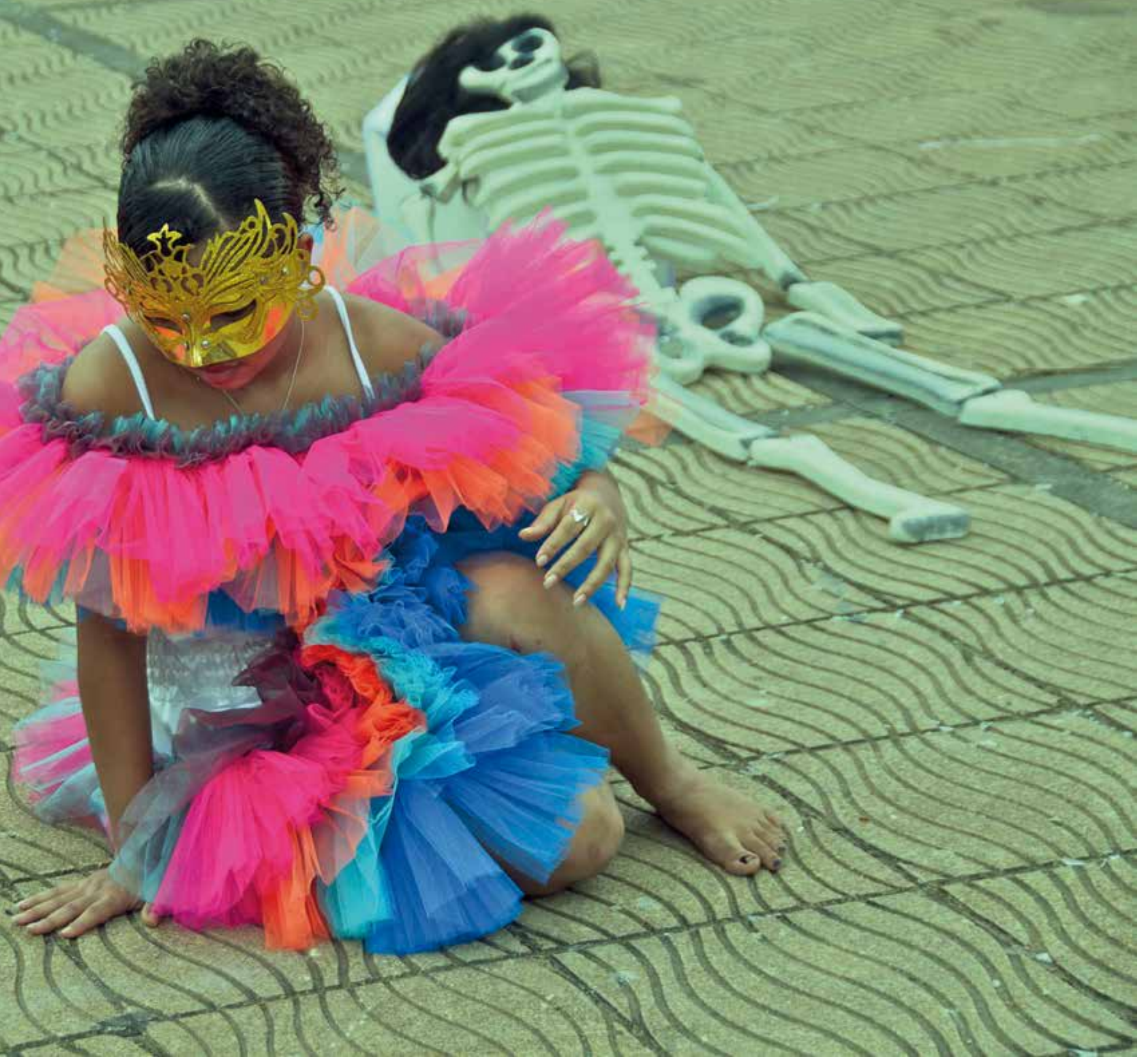

lenguaje: paradigmático y narrativo, el primero relacionado con el lenguaje de las ciencias, y el segundo con las formas narrativas aproximadas y asociadas con las artes y las humanidades, haciendo énfasis en las sensaciones. Según Brunner (1998), las formas narrativas valoran lo metafórico y la polisemia a la hora de transmitir significados. El lenguaje narrativo brinda credibilidad antes que verdad en términos científicos de universales paradigmáticos y absolutos; la narrativa es sensible al contexto, aplicable a lo local y a lo particular, donde el discurso narrativo está abierto a la interpretación.

Para Eisner (2002) los relatos y las narrativas contenidas en los distintos lenguajes artísticos han surgido como un medio potencialmente poderoso mediante el cual alumnos y docentes pueden adquirir conocimientos. Así mismo, para el autor los procesos de construcción de imágenes pueden ayudar a los niños a descubrir una parte de sí mismos que casi siempre está por debajo de la conciencia; a través del arte se 
enseña o ayuda a descubrir ciertas dimensiones de sí mismos, "donde la experiencia es la base sobre la cual se construye el significado, y que esa experiencia depende en alto grado de nuestra capacidad de entrar en contacto con el mundo cualitativo que habitamos" (2002, p. I72). Siguiendo al autor, este mundo cualitativo es inmediato antes de ser mediado, presentacional antes de representacional y sensorial antes de ser simbólico.

Ahora bien, dado que las artes son constituidas por diferentes lenguajes, cada lenguaje con sus distintas formas de representación posibilitan diferente formas de conocimiento: "cada forma de lenguaje tiene su función epistémica”. Para autores como Goodman (1976) y Eisner (2002), la diversidad de los lenguajes artísticos permite la posibilidad de aumentar la variedad y profundidad de los significados que la gente extrae de su vida, en la medida que hay tantos mundos como maneras de describirlos, representarlos e interpretarlos. El acto mismo de representación es una transformación de un estado interno en el mundo público, ya que la representación implica externalizar lo interno, hacer público lo que es privado. Las formas de representación implican sistemas simbólicos, con funciones epistémicas (Cassirer, Langer, citada en Goodman, 1976); se produce pensamiento a través de las formas de representación, más allá de la palabra y el número como formas dominantes, donde los seres humanos son hacedores de significado, y las formas que contiene el arte y la cultura se inventaron para transmitir significados que no podían transmitirse de ningún otro modo.

Las artes plásticas y visuales aparecen como otro sistema de significación, a través de formas visuales y audiovisuales, y tiene protagonismo la experiencia humana desde los sentidos, lo sensible, la estética:

\begin{abstract}
Alfabetizarse, en el sentido más amplio del término, quiere decir aprender a tener un acceso significativo a las formas de vida que estos sistemas de significado hacen posible, para el caso el arte, lo que deberíamos desarrollar en nuestras escuelas no es solo una serie de destrezas alfabéticas limitadas a una gama restringida de sistemas de significado, sino un espectro de alfabetismos que permita a los alumnos a participar, disfrutar, y encontrar significado en las grandes formas a través de las cuales se ha constituido el significado. (Eisner, 2002, p.3I).
\end{abstract}

Según Eisner (2002), hay mucho que aprender de los cuentos, las imágenes y los poemas, por lo cual resulta irónico que cualidades tan fundamentales e influyentes como las que constituyen el arte hayan sido descuidadas en el discurso de la metodología de la investigación, en el que los académicos han establecido tajantes diferencias entre el arte y la ciencia, asumiendo que la ciencia social no tiene nada que ver con el arte; se genera así, en palabras del autor, "no solo una concepción provinciana del arte, sino una visión distorsionada de la ciencia. Es una perspectiva que no beneficia a la investigación educativa (p.220)":
Tal vez el creciente interés en los aportes cognitivos de las artes, presagie un nuevo comienzo. Tal vez empezamos a entrar, por fin, en una etapa de la investigación educativa en que los investigadores consideraran las artes no solo como una parte fundamental de la escolaridad, sino también como un aspecto básico de la excelencia de la ciencia social. (Eisner, 2002, p. 220).

\section{Investigación pedagógica a través de las artes plásticas y visuales}

Como se ha mencionado, las metodologías de investigación educativa artística pueden ser muy diversas, porque la investigación en educación artística se define por el problema que enfrenta: el aprendizaje artístico. Dado que al arte lo constituyen diferentes lenguajes, cada lenguaje implicará tanto formas específicas, herramientas y objetivos propios, como su afinidad y coherencia entre los problemas que trata y el modo de enfrentarse a ellos (sin que ninguno de los métodos planteados pueda acaparar o excluir en su totalidad al otro del dominio del campo investigativo).

Sin embargo, y como se ha señalado, para el caso en cuestión se hará referencia específicamente a las artes plásticas y visuales, en las que la educación artística trata esencialmente con formas visuales, sistemas de comunicación visual y audiovisual; para ello se requiere tener en cuenta tres líneas de desarrollo que han discurrido en paralelo, aunque con frecuentes zonas de contacto, como antecedentes clásicos de un posible método de investigación pedagógico a través de las artes plásticas y visuales, las cuales son: la investigación basada en imágenes o antropología visual, desde el Congreso Internacional de Antropología Visual en I973; la recuperación de la subjetividad tal como se plantea desde las narrativas personales o la autoetnografía; y la investigación basada en artes. Los aspectos característicos y comunes entre las tres líneas son:

Énfasis en las cualidades estéticas de las formas de presentación y representación, coherencia entre formas y contenidos de los resultados, y nuevas posibilidades a formas multimediales de presentación de los resultados.

Las estrategias de indagación son las propias de las artes y la cultura visual, así como los lenguajes y formas de representación usadas son visuales y audiovisuales (fotografía, dibujo, video, pintura, arquitectura, animación, etc.). Basadas en los procesos de creación de imágenes, más allá de crear nuevos estilos o formas artísticas supone el disfrute y el aprovechamiento de los modos propios del conocimiento artístico para esclarecer problemas de la educación, en general, y de la educación artística plástica visual, en particular.

- La investigación informada en arte en contraposición a la tradición de la investigación cualitativa, en la que 
las imágenes son solo accesorias, propone un modelo de investigación que une procesos y formas de representación de las artes visuales con la indagación cualitativa, de manera que los productos de investigación reflejan una variedad de formas artísticas visuales y audiovisuales (fotografía, instalaciones, collages, films, video, escultura, multimedia).

Mediante las narrativas visuales, específicamente como procesos de creación de imágenes visuales y audiovisuales en diferentes técnicas, medios y soportes, es posible recuperar la subjetividad, dar sentido a las experiencias y ordenarlas como escrituras del yo en tanto formas de representación que tienen en común la capacidad de organizar y transformar la experiencia de lo personal, para reconstruir un discurso de conocimiento en que se relaciona la teoría y la práctica; se establece así una relación dialéctica entre "lo pensado" y "lo realizado" a través de la solución de problemas concretos.

- Los nuevos modos de representación amplían los modos de ver y abordar los problemas, e incrementan las posibles respuestas o rutas de encuentro, en la medida en que pueden ser más evocativos que denotativos al tener multiplicidad de interpretaciones.

Trascender el análisis de la experiencia personal para una mayor comprensión de la realidad educativa a través de la interpretación de significados.

Para finalizar, y una vez esbozados algunos precedentes de lo que podría plantearse como método de investigación pedagógico a través de las artes visuales, asumiendo que si bien no es lo mismo hablar de investigación educativa e investigación pedagógica, y de investigar desde o sobre las artes, para el caso desde o sobre la educación artística, se propone una investigación pedagógica a través de las artes visuales, aclarando que, aunque pareciera un juego de palabras peyorativo, es mucho más que eso. Implica, como ya se vio, diferenciar dos campos de conocimiento, dos tipos de investigación e investigadores, los escenarios, protagonistas, objetos de estudio, y, por ende, las maneras de asumir y comprender tanto la investigación, sus significados y representaciones, como sus ámbitos de realidad, los temas, asuntos y problemas sobre los que centra su atención, las formas específicas, las herramientas y los objetivos propios de este, y su afinidad y coherencia entre los problemas que trata y el modo de enfrentarse a ellos.

Según Guzmán-Valenzuela (2014, p. 19), Las expresiones "investigar acerca de la realidad" e "investigar desde la realidad" podrían mostrar la distinción tic/emic; investigar "acerca de" la realidad denota una posición más lejana o externa a la realidad e investigar "desde" indica una más cercana. En el primer caso, el investigador hará descripciones y elaborará interpretaciones más alejadas de la experiencia de los participantes (aunque siempre en diálogo con esta) y conectadas con marcos interpretativos y ontoepistémicos afines a su disciplina, lo cual permite que estas interpretaciones sean más abstractas.

En el segundo caso, el investigador estará "más atento" a las visiones y los significados de los participantes, con especial atención a sus prácticas sociales y diálogos cotidianos en contextos singulares de donde emergen significados creados y negociados e intenciones que organizan y revelan la experiencia como un proceso (Huberman Miles, 1994). Para lograrlo, el investigador realizará descripciones densas (Geertz, I973), con cuidado de los detalles, la complejidad y los significados situados en la vida diaria, privilegiará una estancia prolongada en el campo o analizará y validará los resultados del estudio con los propios participantes.

Así, la investigación pedagógica desde las artes visuales supone la investigación del maestro investigador en el escenario donde se desarrollan los procesos de enseñanza-aprendizaje, para el caso de la escuela-el aula-taller-laboratorio, las vicisitudes del ser y el quehacer enseñante y aprendiz que en dichos contextos se presenta desde y a través de una disciplina, o para el caso del lenguaje artístico específico, las maneras de aprenderlo y conocerlo, y de aprender y conocer al otro y lo otro desde dicho lenguaje, que configurará o consolidará las formas, medios, técnicas y objetivos propios del lenguaje investigado.

Ahora bien, según Eisner (2002) es imperativo lograr una agenda de investigación para el campo de la educación artística, desde la cual se puedan plantear rutas y mapas metodológicos, propios para el campo y especialmente para la especificidad de disciplinas que maneja:

Los educadores se interesan en facilitar el aprendizaje y crear ciertas formas intrínsecamente satisfactorias de experiencias, y lo hacen de acuerdo con determinados valores. La educación es en esencia una empresa normativa. No se ocupa del mero cambio, sino del mejoramiento de la vida. (Eisner, 2002, p. 32).

\section{Referencias}

Brunner, J. S. (1998). Realidad mental y mundos posibles: los actos de la imaginación que dan sentido a la experiencia. Barcelona: Gedisa.

Calvo, G., Camargo-Abello, M. y Pineda-Báez, C. (2008). ¿Investigación educativa o investigación pedagógica? El caso de la investigación en el Distrito Capital. Magis, Revista Internacional de Investigación en Educación, I, I63-I74.

Denzin, N. K. (20I2a). El campo de la investigación cualitativa: manual de investigación. Vol. I. Barcelona: Gedisa. 
Denzin, N. K. (20I2b).Paradigmas y perspectivas en disputa: manual de investigación cualitativa, volumen II. Barcelona: Gedisa.

Dewey, John. (2008). El arte como experiencia. Barcelona.Paidós

Eisner E. W. (1998a). El ojo ilustrado: indagación cualitativa y mejora de la práctica educativa. Barcelona. Paidós.

Eisner, E. W. (1998b) Cognición y curriculum: una visión nueva. Buenos Aires: Amorrortu editores.

Eisner, E. W. (1995). Educar la visión artística. Barcelona. Paidós.

Eisner, E. W. (2002). La escuela que necesitamos: ensayos personales. Buenos Aires: Amorrortu Editores.

Elliot, J. (2005). La investigación-acción en educación. Madrid: Morata.

Gardner H. (2005). Inteligencias múltiples. Barcelona: Paidós

Goodman, N. (1976). Los lenguajes del arte: aproximación a la teoría de los símbolos. Barcelona: Seix Barral.

Guzmán-Valenzuela, C. M. (20I4). Polos epistemológicos, uso y construcción de teoría en investigación cualitativa en educación. Magis, Revista Internacional de Investigación en Educación, 7(14), 15-28.

Hernández, F. (2006). Bases para un debate sobre investigación artística. Madrid: Ministerio de Educación y Ciencia.

Herrera-González, J. D. (20I0). La formación de docentes investigadores: el estatuto científico de la investigación pedagógica. Magis, Revista Internacional de Investigación en Educación, 3(5), 53-62.

Malinowski, Bronislaw. (1984). Una teoría científica de la cultura. Madrid : Sarpe

Mead, Margaret. (1975). La antropología y el mundo contemporáneo. Buenos Aires: Eds. Siglo Veinte.

Sánchez, Z. P. (20I4). Antecedentes de la educación artística plásticas visual en Colombia: Revisión de revistas científicas. En D. Calderón (ed.), Lenguaje, cultura e Investigación: problemas emergentes en educación (pp. I05-I29). Bogotá: U.D.

Touriñán-López, J. M. (2008). Teoría de la educación: investigación disciplinar y retos epistemológicos. Magis, Revista Internacional de Investigación en Educación, I, I75-I94.

Vasilachis de Gialdino, I. (2009). Estrategias de investigación cualitativa. Barcelona: Gedisa.

Viadel, M. R. (2005). Investigación en educación artística: temas, métodos y técnicas de indagación sobre el aprendizaje y la enseñanza de las artes y culturas visuales. Granada: Universidad de Granada.

Zulma Sánchez Beltrán, Maestra en Artes Plásticas y Visuales de la Academia Superior de Artes de Bogotá de la Universidad Distrital Francisco José de Caldas (Bogotá, Colombia). Magíster en Historia y Teoría del Arte, la Arquitectura y la Ciudad de la Universidad Nacional de Colombia (Bogotá, Colombia). Estudiante del Doctorado Interinstitucional en Educación DIE de la Universidad Distrital Francisco José de Caldas, Universidad del Valle y Universidad Pedagógica Nacional (Bogotá, Colombia). Docente de cátedra en la Licenciatura en Artes Visuales de la Universidad Pedagógica Nacional (Bogotá, Colombia). Docente de Artes Plásticas y Visuales de la media, en la Secretaria de Educación Distrital.

nadaizmoz@yahoo.com

zpsanchezb@pedagogica.edu.co 